\title{
REUSABLE FABRIC MASKS AGAINST COVID-19
}

\author{
Mustafa Erdem ÜREYEN ${ }^{1,2}$ (D), Nuran ZARIF ${ }^{3}$ (D), Elif KAYNAK ${ }^{2,4}$ * (iD) \\ ${ }^{1}$ Textile and Fashion Design Dept., Faculty of Architecture and Design, Eskisehir Technical University, Eskisehir, Turkey \\ ${ }^{2}$ Advanced Technologies Research Center, Eskisehir Technical University, Eskisehir, Turkey \\ ${ }^{3}$ Grad. School of Sciences, Eskisehir Technical University, Eskisehir, Turkey \\ ${ }^{4}$ Chemical Engineering Dept., Faculty of Engineering, Eskisehir Technical University, Eskisehir, Turkey
}

\begin{abstract}
Upon the outbreak of the COVID-19, community wide mask wearing has become an important tool to prevent the spread of the virus. The use of disposable masks -that are generally produced of three or more layers of synthetic nonwovens- by the general public is being questioned from an environmental and waste perspective. Conventional textile fabrics, on the other hand, may not provide the desired level of protection against the virus. In this study three layer fabric mask structures having a middle layer of nonwoven $\left(100 \mathrm{~g} / \mathrm{m}^{2}\right.$ or $\left.120 \mathrm{~g} / \mathrm{m}^{2}\right)$ sandwiched between knitted polyester fabrics were prepared. The particle filtration and breathability properties of the fabric assemblies were investigated. In order to prevent bacterial growth and enable safer use, the outer layer was antibacterial and water repellent functionalized. The middle layer was also antibacterial treated. The air permeability of the three layer fabric structure with an antibacterial nonwoven $\left(100 \mathrm{~g} / \mathrm{m}^{2}\right)$ middle layer and an antibacterial and water repellent outer layer was $\geq 961 / \mathrm{m}^{2} / \mathrm{s}$. The particle filtration efficiency was $23 \%$ when tested for $0.3 \mu \mathrm{m}$ $\mathrm{NaCl}$ aerosol particles. The particle filtration efficiency was not reduced after washing up to 20 cycles.
\end{abstract}

Keywords: Face mask, Fabric, Antibacterial, Air permeability

\section{INTRODUCTION}

Before the global pandemic of Coronavirus Disease 2019 (COVID-19), the use of masks and respirators had been mostly limited to the industrial and healthcare settings where the protection of wearers from exposure to dangerous substances (chemical or biological) is required. There are well established national and international standards on the requirements of medical/surgical masks and respirators. For instance, the Turkish Standard TS EN $149+$ A1 defines the requirements for respiratory protective devices and presents a classification (FFP1, FFP2 and FFP3) based on the performance criteria [1]. The classification of medical face masks (Type I, Type II, Type IIR) are defined in TS EN 14683+AC:201909 based on the assessment of bacterial filtration efficiency $(\%)$, differential pressure $\left(\mathrm{Pa} / \mathrm{cm}^{2}\right)$, microbial cleanliness (cfu/g) and splash resistance (kPa, only for Type IIR) [2]

Upon the outbreak of COVID-19, community-wide mask wearing was recommended by the authorities as the new coronavirus (SARS-CoV-2) mainly spreads in the form of liquid particles (liquid droplets, aerosols) from the mouth and nose, and mask wearing could reduce the risk of transmission of the virus $[3,4]$. This has triggered the demand for face masks and eventually led to a shortage in the supply of face masks that are compliant with the previously established standards [5]. The use of fabric masks (barrier masks, community masks, DIY masks) by the general public has been debated not only due to the shortage of medical masks and respirators, but also because the fabric masks pose lower risk of adverse health effects $[6,7]$. Surgical masks and N95 masks were found to cause discomfort as they prevent normal transpiration and increase perspiration [8]. The reports on the adverse skin reactions and sensation of dry nose due to the prolonged use of medical/surgical masks and respirators are not rarely found [9-11]. Several organizations, both regional and international, have issued guides and standards on the minimum requirements of the fabric masks [12-15]. Although the testing methods and/or

*Corresponding Author:elifkaynak@eskisehir.edu.tr

Received: 02.08.2021 Published: 30.11.2021 
classifications vary, the published documents address three essential parameters: filtration, breathability and fit. In the absence of systematically reported data on the filtration performance of various textile fabrics/structures, most of the studies conducted so far have focused on the filtration performance of the masks $[16,17]$. On the other hand, breathability is just as important due to the concerns associated to difficulty in breathing [6]. There are a few works concerned with both filtration and breathability performance of the fabric masks [18].

The increased use of disposable medical masks/respirators that are produced of several layers of nonwoven fabrics has also been raising concerns from an environmental and waste perspective [19]. The re-use or extended use of masks has also been questioned. The risk of bacterial growth on the mask due to successive use may also lead to serious health problems. The antimicrobial treatment of fabrics can provide efficient protection against microorganisms and address some of the problems related to the extended use of fabric masks [20]. Among other antibacterial agents, silver doped calcium phosphate based inorganic powders were successfully used for the antibacterial treatment of textiles [21]. Such inorganic structures are expected to pose lower toxicity as they tend to release silver ions at a relatively slow rate [22].

In this study the potential of the knitted polyester fabrics for the production of face masks has been investigated. Three layer fabric structures were designed to provide efficient filtration performance without compromising breathability. In order to reduce the risk of bacterial growth upon use, the middle and outer layers were antibacterial (A) treated. A water repellent (S) finish was applied on the outer layer to reduce the hydrophilicity of the polyester fabric. The performance of the fabric structure after washing has also been assessed to put forth the potential of mask for re-use after washing.

\section{MATERIALS AND METHODS}

Polyester (PET) knitted fabrics and 70\% polyester (PET)-30\% polyamide (PA) nonwoven fabrics were supplied by Meyteks Textile, Turkey and Mogul Co. Ltd, Turkey. Fabric properties are included in Table 1. For antibacterial treatment, an aqueous solution of silver doped calcium phosphate based antibacterial agent (PAG-C-75, Nanotech, Turkey) and an acrylic resin (ORGAL NA 430, Organik Kimya, Turkey) was prepared at $\mathrm{pH}=5-5.5$. The fabrics were passed through this solution and squeezed with a laboratory padder (ATC-F350, Ataç, Turkey) to achieve $85 \%$ pick-up. After drying at $110^{\circ} \mathrm{C}$ for three minutes, the knitted fabrics were treated by a fluorocarbon based water repellent agent (Nuva 2110 , Clariant, Turkey) to achieve $90 \%$ pick-up. Curing was performed at $160^{\circ} \mathrm{C}$ for three minutes.

Table 1. Fabric properties

\begin{tabular}{lccccc}
\hline Code & Type & Composition & $\begin{array}{c}\text { Areal Density } \\
\left(\mathbf{g} / \mathbf{m}^{2}\right)\end{array}$ & $\begin{array}{c}\text { Thickness } \\
(\boldsymbol{\mu m})\end{array}$ & $\begin{array}{c}\text { Bulk Density } \\
\left(\mathbf{g} / \mathbf{c m}^{\mathbf{3}}\right)\end{array}$ \\
\hline N1 & Nonwoven & $70 \%$ PET-30\% PA & 100 & 260 & 0.4 \\
N2 & Nonwoven & $70 \%$ PET-30\% PA & 120 & 330 & 0.4 \\
N3 & Nonwoven & $70 \%$ PET-30\% PA & 80 & 250 & 0.3 \\
M1 & Knitted & $100 \%$ PET & 128 & 430 & 0.3 \\
M2 & Knitted & $100 \%$ PET & 114 & 400 & 0.3 \\
M3 & Knitted & 92\% PET-8\% EL & 237 & 580 & 0.4 \\
\hline
\end{tabular}


The fabric surfaces were analyzed by a light microscope (Discovery V20, Zeiss, Germany) equipped with a digital camera (Axiocam ERc 5s, Zeiss, Germany). Fabrics were tested for antimicrobial activity (ASTM E2149:2020) using Escherichia coli (ATCC 25922) as the test organism. The initial bacteria concentration was $1.5 \times 10^{5} \mathrm{cfu} / \mathrm{ml}$. The $\%$ reduction (R) was calculated according to Equation 1 where $\mathrm{A}$ and $\mathrm{C}$ are the number of colony-forming units in the test specimen and control (untreated) specimen in cfu/ml, respectively, after the contact time ( 24 hours).

$$
R \%=\frac{C-A}{C} \times 100
$$

In order to resemble mask assemblies, three types of fabric structures (I, II, III) each having three layers of fabric were prepared as shown in Figure 1. For each assembly the inner layer fabric that would be in contact with the mouth, nose and skin was of $100 \%$ polyester (M1) and used without any further treatment. Structure Type I is composed of untreated fabric layers. Structure Type II represents the samples which consist of a middle layer of PET/PA blend nonwoven (N1 or N2) and an outer layer of a knitted polyester fabric, both treated with the antibacterial agent. Structure Type III represents the samples which consists of a middle layer of antibacterial treated PET/PA blend nonwoven (N1 or N2) and an outer layer of antibacterial and water repellent treated polyester. Fabrics and fabric structures were tested for breathability according to TS 391 ISO 9237 using an air permeability tester (Proser, Turkey) at a pressure drop of $100 \mathrm{~Pa}$. Three measurements were collected from different parts of each sample and the average results were reported.

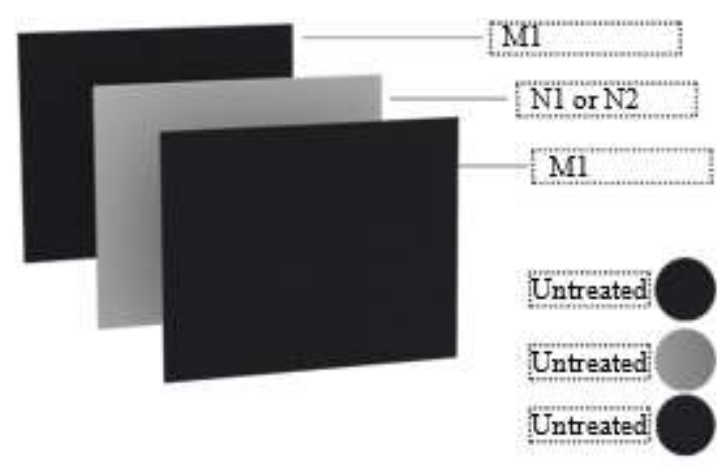

Type I

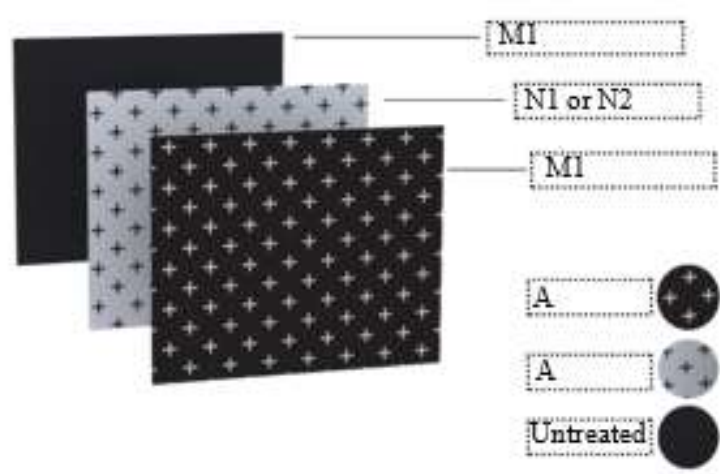

Type II

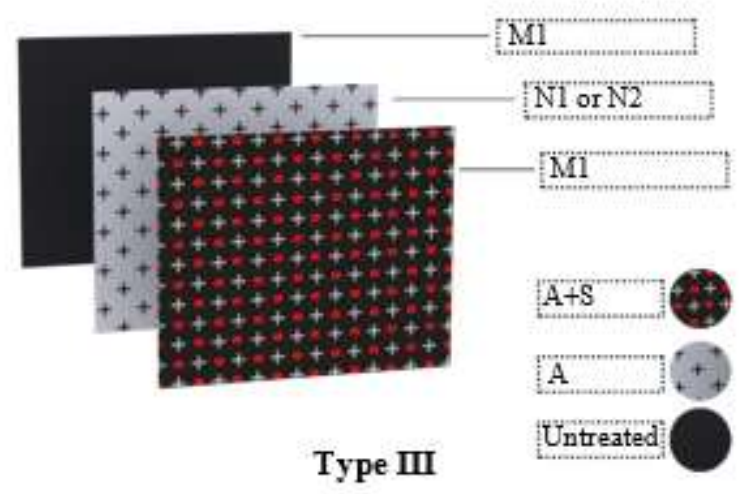

Figure 1. Three layer fabric structures (A: Antibacterial S: Water Repellent)

The particle filtration efficiency $(\eta)$ of three layer structures was tested with an automated filter tester (8130a, TSI, USA) using $\mathrm{NaCl}$ aerosol particles of $0.3 \mu \mathrm{m}$ at a flow rate of $95 \mathrm{~L} / \mathrm{min}$ (face velocity of 
$15.8 \mathrm{~cm} / \mathrm{sec}$ ). The filtration efficiency was calculated using Equation 2 where $C_{u}$ and $C_{d}$ are the aerosol concentrations at the upstream and downstream, respectively.

$$
\eta \%=\frac{C_{u}-C_{d}}{C_{u}} \times 100
$$

Washing was performed according to ISO 6330-2002 5A program in a wascator (FOM 71 CLS, Electrolux, Sweden) and the durability was tested after 20 washing cycles.

\section{RESULTS AND DISCUSSION}

\subsection{Breathability}

Air permeability is often used to evaluate the breathability of textile fabrics [23]. The air permeability values of different fabrics, measured as received, are given in Figure 2.

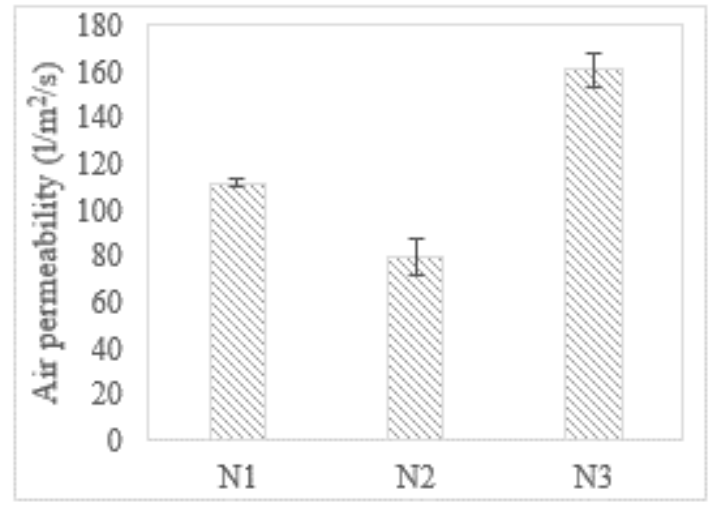

(a)

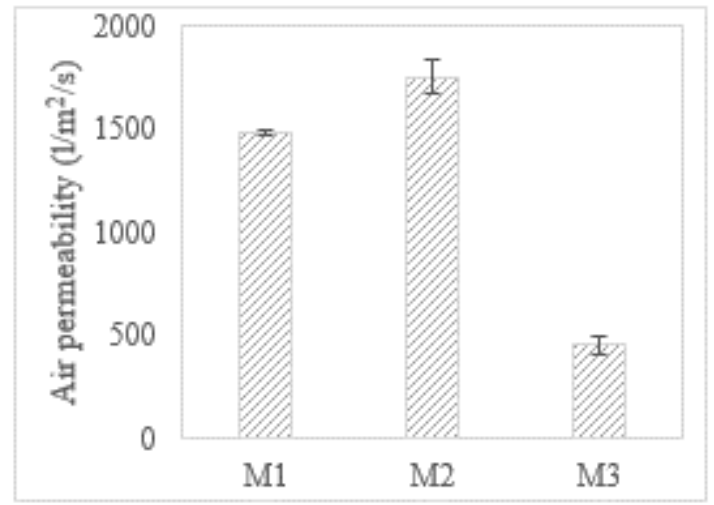

(b)

Figure 2. Air permeability of fabrics

Among the most important factors that control the air permeability of a fabric are, areal density, thickness and bulk density [24, 25]. As can be seen in Figure 2 (a), for the PET/PA blended nonwoven fabrics (N1, N2 and N3), as the areal density, bulk density and thickness increases the air permeability decreases. When compared to M1, sample M2 has a lower areal density and thickness and thus higher air permeability (Figure 2(b)). As can be seen in Figure 3 (c), the sample M3 which has the highest areal density, bulk density and thickness, also has a less porous structure which resulted in a lower air permeability. The air permeability measurement results of three layer fabric structures are given in Table 2. Each sample code begins with the outer layer fabric type, the middle and inner layer fabrics were mentioned consecutively. The letters "A" and/or "S" following the fabric type denote the treatment applied to that fabric. The air permeability of the fabric structure decreased when the areal density of the middle (nonwoven) layer was increased. The air permeability of structures having antibacterial treated layers were higher than those having only untreated layers. This may be due to the heat applied during drying/fixation which damage the nonwoven fabric structure and loosen the pores (Figure 3 (e)). The air permeability of $\mathrm{N} 1$ after antibacterial treatment was increased by $37 \%$, whereas, such an increase was not observed for M1. Nevertheless, the air permeability of Type II and Type III samples (M1AN1AM1, M1ASN1AM1, M1AN2AM1, M1ASN2AM1) were $\geq 961 / \mathrm{m}^{2} / \mathrm{s}$ which is the minimum value of air permeability specified in CWA 17553:2020 [15]. The air permeability values of fabric structures, whether treated or untreated, were reduced gradually upon washing possibly due to fabric shrinkage and felting (Figure 3 (f)). 


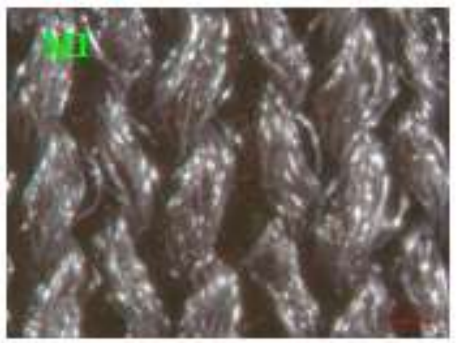

(a)

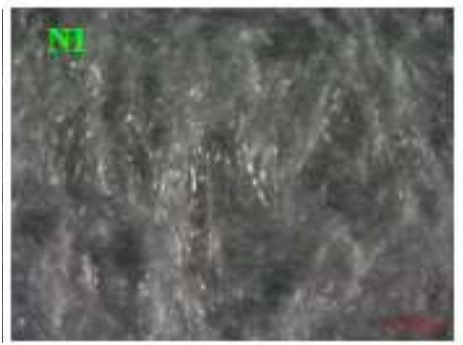

(d)

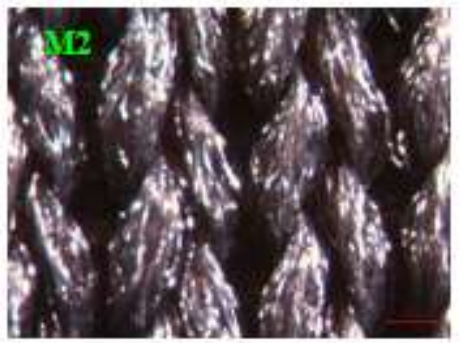

(b)

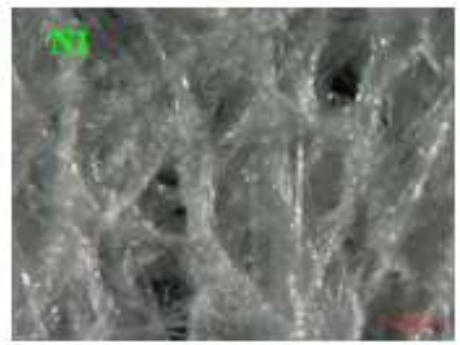

(e)

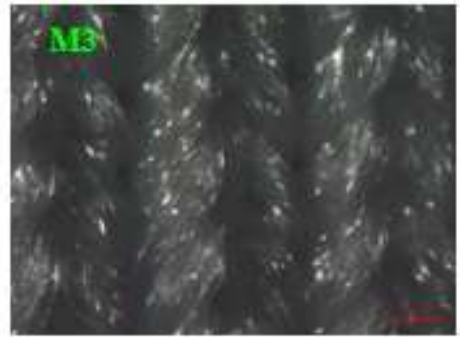

(c)

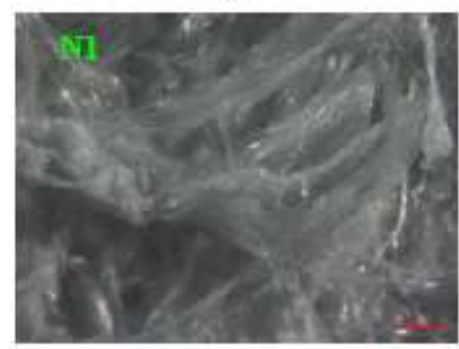

(f)

Figure 3. Microscopy images of untreated a) M1, b) M2, c) M3, d)N1, e) AB treated N1, f) AB treated N1 after 20 washing cycles at $50 \mathrm{X}$ magnification.

Table 2. Air permeability of three layer fabric structures (W:Washing cycle, SD:standard deviation)

\begin{tabular}{|c|c|c|c|c|c|}
\hline Sample Code & $\begin{array}{l}\text { Middle } \\
\text { Layer } \\
\text { Fabric } \\
\end{array}$ & $\begin{array}{c}\text { Structure } \\
\text { Type }\end{array}$ & $\begin{array}{c}\text { Air permeability } \\
\text { (before washing) } \pm \text { SD } \\
\mathbf{l} / \mathbf{m}^{2} / \mathbf{s} \\
\end{array}$ & $\begin{array}{c}\text { Air permeability } \\
(\text { after } 5 \mathrm{~W})) \pm \text { SD } \\
\mathbf{1} / \mathbf{m}^{2} / \mathbf{s} \\
\end{array}$ & $\begin{array}{c}\text { Air permeability } \\
(\text { after } 20 \mathrm{~W})) \pm \text { SD } \\
\mathbf{l} / \mathbf{m}^{2} / \mathbf{s} \\
\end{array}$ \\
\hline M1N1M1 & N1 & $\mathrm{I}$ & $91.7 \pm 5.7$ & $77.1 \pm 5.8$ & $75.4 \pm 3.3$ \\
\hline M1AN1AM1 & $\mathrm{N} 1$ & II & $134.5 \pm 9.1$ & $101.7 \pm 8.1$ & $82.5 \pm 4.3$ \\
\hline M1ASN1AM1 & $\mathrm{N} 1$ & III & $145.8 \pm 5.6$ & $107.1 \pm 4.2$ & $83.5 \pm 1.8$ \\
\hline M1N2M1 & $\mathrm{N} 2$ & I & $72.3 \pm 6.5$ & $69.5 \pm 6.3$ & $67.7 \pm 0.9$ \\
\hline M1AN2AM1 & $\mathrm{N} 2$ & II & $96.8 \pm 9.0$ & $88.2 \pm 7.1$ & $69.1 \pm 6.1$ \\
\hline M1ASN2AM1 & $\mathrm{N} 2$ & III & $96.8 \pm 10.2$ & $70.8 \pm 4.9$ & $65.6 \pm 3.2$ \\
\hline
\end{tabular}

\subsection{Particle Filtration}

The particle filtration efficiencies were calculated using Equation 1, for two different fabric structures (Type I and Type III in Figure 1) having N1 or N2 fabric as their middle layers. The calculated values are presented in Figure 4. The particle filtration efficiency of sample M1N2M1 (36.2\%) was higher than that of M1N1M1 (32.2\%). In comparison to M1N1M1, the better filtration performance of M1N2M1 may be attributed to the higher grammage and thickness of the middle layer nonwoven (N2) used in the structure [26]. The filtration efficiencies of both samples were reduced after treatment. After 20 washing cycles, the filtration efficiency of treated samples (M1ASN1AM1, M1ASN2AM1) were enhanced. These results are in good agreement with the decreasing tendency of air permeability after washing. In this study the tests were carried out using $\mathrm{NaCl}$ aerosol particles of $0.3 \mu \mathrm{m}$. Although the current European standards for fabric masks specify the minimum filtration efficiency (90\%) to particles of 3 $\mu \mathrm{m}$ [15], aerosol particles of smaller size were specified in some other standards for respirators and face 
masks [27]. Previous studies have shown that the filtration efficiency increases significantly with the increasing particle size of the aerosol used for testing [28, 29].

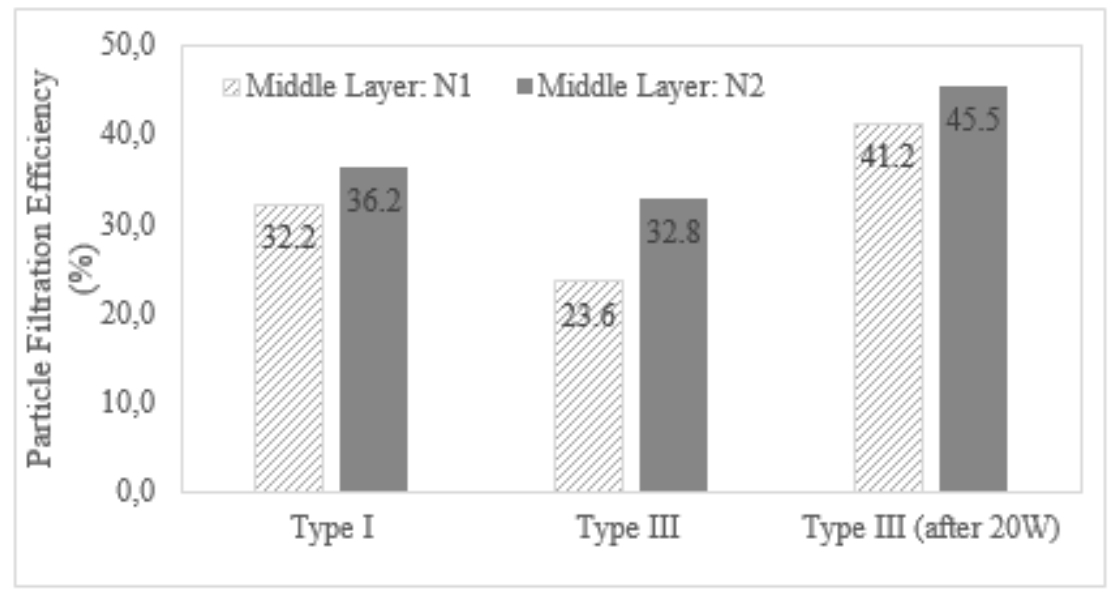

Figure 4. Particle filtration efficiency of three layer structures (W: Washing cycle)

\subsection{Antimicrobial Activity}

The fabrics N1, N2 and M1 were tested for antimicrobial activity after being treated with antibacterial and water repellent agents. The treated samples were washed according to the standard washing procedure and the washed samples were also tested to evaluate the effect of washing on antimicrobial activity. The antimicrobial activity test results are presented in Table 3. The PET/PA blended nonwoven samples exhibited higher antimicrobial activity than polyester knitted fabric. This may be due to larger surface areas of nonwoven fabrics which enable them to accommodate higher amounts of antibacterial agent [30]. The reduction in antimicrobial activity also occurred at a greater extent in polyester knitted fabric after washing when compared to the samples PET/PA blended nonwoven samples.

Table 3. Antimicrobial test results

\begin{tabular}{lccc}
\hline Code & Treatment & $\begin{array}{c}\text { Reduction (\%) } \\
\text { Before Washing }\end{array}$ & $\begin{array}{c}\text { Reduction (\%) } \\
\text { After 20 Washing Cyles }\end{array}$ \\
\hline N1 & A & 99.99 & 99.64 \\
N2 & A & 99.99 & 98.85 \\
M1 & A+S & 97.73 & 95.91 \\
\hline
\end{tabular}

\section{CONCLUSION}

Antibacterial and/or water repellent finishes may be useful in reducing the health risks associated with the extended use of masks during the pandemic. However, these treatments may lead to significant changes in the fabric structure and porosity and thus, breathability and filtration properties. It was shown that for the three layer fabric assemblies, the filtration efficiency to $0.3 \mu \mathrm{m}$ particles was reduced after functional treatments but increased after washing. The increase in filtration performance after washing might be promising in terms of reuse. The number of uses on the other hand is limited by the reduction in air permeability. Type II and Type III fabric structures using $100 \mathrm{~g} / \mathrm{m}^{2}$ nonwoven could comply with the current air permeability requirement ( $\geq 96 \mathrm{l} / \mathrm{m}^{2} / \mathrm{s}$ ) up to 5 washing cycles. 


\section{ACKNOWLEDGEMENTS}

This work was supported by the Eskisehir Technical University Scientific Research Projects Commission [grant number 20GAP073] and Scientific and Technological Research Council of Turkey (TÜBİTAK) 2247-C STAR program.

\section{CONFLICT OF INTEREST}

The authors stated that there are no conflicts of interest regarding the publication of this article.

\section{REFERENCES}

[1] TSE. Solunumla İlgili Koruyucu Cihazlar -Parçaciklara Karşi Koruma Amaçli Filtreli Yarim Maskeler - Özellikler, Deneyler ve İşaretleme TSE EN 149 + A1: 2010.

[2] TSE. Tıbbi yüz maskeleri - Gereklilikler ve deney yöntemleri TS EN 14683+AC: 2019.

[3] Cheng VC, Wong SC, Chuang VW, So SY, Chen JH, Sridhar S, To KK, Chan JF, Hung IF, Ho $\mathrm{PL}$, et al. The role of community-wide wearing of face mask for control of coronavirus disease 2019 (COVID-19) epidemic due to SARS-CoV-2. J Infect, 2020;81:107-14.

[4] WHO. Mask use in the context of COVID-19: interim guidance. 2020.

[5] OECD. The Face Mask Global Value Chain in the COVID-19 Outbreak: Evidence and Policy Lessons, 2020.

[6] ECDC. Using face masks in the community: first update effectiveness in reducing transmission of COVID-19. Stockholm2021.

[7] Techasatian L, Lebsing S, Uppala R, Thaowandee W, Chaiyarit J, Supakunpinyo C, Panombualert S, Mairiang D, Saengnipanthkul S, Wichajarn K, et al. The Effects of the Face Mask on the Skin Underneath: A Prospective Survey During the COVID-19 Pandemic. J Prim Care Community Health, 2020;11:2150132720966167.

[8] Purushothaman PK, Priyangha E, Vaidhyswaran R. Effects of Prolonged Use of Facemask on Healthcare Workers in Tertiary Care Hospital During COVID-19 Pandemic. Indian J Otolaryngol Head Neck Surg,2020:1-7.

[9] Hu K, Fan J, Li X, Gou X, Li X, Zhou X. The adverse skin reactions of health care workers using personal protective equipment for COVID-19. Medicine (Baltimore), 2020;99:e20603.

[10] Xie Z, Yang YX, Zhang H. Mask-induced contact dermatitis in handling COVID-19 outbreak. Contact Dermatitis, 2020;83:166-7.

[11] Yu J, Chen JK, Mowad CM, Reeder M, Hylwa S, Chisolm S, Dunnick CA, Goldminz AM, Jacob $\mathrm{SE}, \mathrm{Wu} \mathrm{PA}$, et al. Occupational dermatitis to facial personal protective equipment in health care workers: A systematic review. J Am Acad Dermatol, 2021;84:486-94.

[12] TSE. Solunumla İlgili Koruyucu Cihazlar -Parçaciklara Karşi Koruma Amaçli Filtreli Yarim Maskeler - Özellikler, Deneyler Ve İşaretleme TSE K 599: 2002. 
[13] AFNOR. Barrier Masks: Guide to minimum requirements, methods of testing, making and use S76-001: 2020.

[14] IPQ. Reusable community mask DNP TS C0042020007: 2020.

[15] CEN. Community face coverings - Guide to minimum requirements, methods of testing and use CWA 17553: 2020.

[16] Konda A, Prakash A, Moss GA, Schmoldt M, Grant GD, Guha S. Aerosol Filtration Efficiency of Common Fabrics Used in Respiratory Cloth Masks. ACS Nano, 2020;14:6339-47.

[17] Tcharkhtchi A, Abbasnezhad N, Zarbini Seydani M, Zirak N, Farzaneh S, Shirinbayan M. An overview of filtration efficiency through the masks: Mechanisms of the aerosols penetration. Bioact Mater, 2021;6:106-22.

[18] Park S, Jayaraman S. From containment to harm reduction from SARS-CoV-2: a fabric mask for enhanced effectiveness, comfort, and compliance. The Journal of The Textile Institute, 2020;115 .

[19] Vanapalli KR, Sharma HB, Ranjan VP, Samal B, Bhattacharya J, Dubey BK, Goel S. Challenges and strategies for effective plastic waste management during and post COVID-19 pandemic. Sci Total Environ, 2021;750:141514.

[20] Pullangott G, Kannan U, S G, Kiran DV, Maliyekkal SM. A comprehensive review on antimicrobial face masks: an emerging weapon in fighting pandemics. RSC Advances, 2021;11:6544-76.

[21] Üreyen ME, Doğan A, Koparal AS. Antibacterial functionalization of cotton and polyester fabrics with a finishing agent based on silver-doped calcium phosphate powders. Textile Research Journal, 2012;82:1731-42.

[22] Üreyen ME, Aslan C. Determination of silver release from antibacterial finished cotton and polyester fabrics into water. The Journal of The Textile Institute, 2016;1-8.

[23] Hu JY, Li YI, Yeung KW. Air permeability. Clothing Biosensory Engineering2006. p. 252-60.

[24] Cook J, Kritzer P. Secondary Batteries - Nickel Systems | Alkaline Battery Separators. In: Garche J, editor. Encyclopedia of Electrochemical Power Sources: Elsevier; 2009; p. 424-51.

[25] Çinçik E, Koç E. An analysis on air permeability of polyester/viscose blended needle-punched nonwovens. Textile Research Journal, 2011;82:430-42.

[26] Cheng S, Muhaiminul ASM, Yue Z, Wang Y, Xiao Y, Militky J, Prasad M, Zhu G. Effect of Temperature on the Structure and Filtration Performance of Polypropylene Melt-Blown Nonwovens. Autex Research Journal, 2020;0.

[27] Jones RM, Rempel D. Standards for Surgical Respirators and Masks: Relevance for Protecting Healthcare Workers and the Public During Pandemics. Ann Work Expo Health, 2021;65:495504. 

8th ULPAS - Special Issue 2021

[28] Sousa-Pinto B, Fonte AP, Lopes AA, Oliveira B, Fonseca JA, Costa-Pereira A, Correia O. Face masks for community use: An awareness call to the differences in materials. Respirology. 2020;25:894-5.

[29] Nallathambi G, Evangelin S, Kasthuri R, Nivetha D. Multilayer nonwoven fabrics for filtration of micron and submicron particles. Journal of Textile Engineering \& Fashion Technology, $2019 ; 5$.

[30] Erdem R, Rajendran S. Influence of Silver Loaded Antibacterial Agent on Knitted and Nonwoven Fabrics and Some Fabric Properties. Journal of Engineered Fibers and Fabrics, 2016;11:38-46. 